\title{
(2) OPEN ACCESS \\ Misoprostol knowledge and distribution in Mexico City after the change in abortion law: a survey of pharmacy staff
}

\author{
Greta Weaver (D) ,' Raffaela Schiavon, ${ }^{2}$ Maria Elena Collado, ${ }^{3}$ \\ Stephanie Küng (D) , ${ }^{4}$ Blair G Darney (D) ${ }^{1}$
}

${ }^{1}$ Obstetrics and Gynecology, Oregon Health \& Science University, Portland, Oregon, USA ${ }^{2}$ Independent Consultant, Mexico City, Mexico

${ }^{3}$ Ipas, Mexico City, Mexico ${ }^{4}$ Ipas, Durham, North Carolina, USA

\section{Correspondence to}

Dr Blair G Darney, Obstetrics and Gynecology, OHSU, Portland, OR 97239, USA; darneyb@ohsu.edu

Received 5 June 2019 Revised 19 September 2019 Accepted 21 September 2019 Published Online First 5 November 2019

\section{Check for updates}

(c) Author(s) (or their employer(s)) 2020. Re-use permitted under CC BY-NC. No commercial re-use. See rights and permissions. Published by BMJ.

To cite: Weaver $\mathrm{G}$, Schiavon $\mathrm{R}_{\iota}$ Collado ME, et al. BMJ Sex Reprod Health

2020;46:46-50.

\begin{abstract}
Objective First-trimester abortion is widely available in Mexico City since legalisation in 2007, but few data exist surrounding pharmacy staff knowledge and sales practices. We describe misoprostol availability, whether a prescription is required, and knowledge of the legal status of abortion and uses for misoprostol among pharmacy staff in Mexico City.
\end{abstract}

Methods Data were collected from 174 pharmacies in Mexico City. One employee at each pharmacy was asked about availability, need for prescription, indications for misoprostol, and sociodemographic information. Our primary outcome was availability of misoprostol. We used descriptive and bivariate statistics to compare knowledge and practices by type of pharmacy and staff gender.

Patients and public involvement No patients were involved in this study.

Results Of the 174 pharmacies, 65 were chain and 109 small independent. Misoprostol was available at $61 \%$ of sites. Only $49 \%$ of independent pharmacies sold misoprostol, compared with $81.5 \%$ of chain pharmacies $(p<0.05)$. Knowledge of indications for misoprostol use was similar. The majority (80\%) of respondents knew that abortion was legal in Mexico City, and 44\% reported requiring a prescription for sale of misoprostol, with no significant difference between male and female staff or by pharmacy type.

Conclusions Availability, requirement of a prescription, and knowledge of indications for use of misoprostol varies among pharmacies, resulting in differential access to medical abortion. Pharmacies may be a good place to target education for pharmacy staff and women about safe and effective use of misoprostol for abortion.

\section{Key messages}

This study explored pharmacy staff knowledge and sales practices related to misoprostol in Mexico City, where firsttrimester abortion was legalised in 2007.

- Our study found that misoprostol was available for sale at $61 \%$ of pharmacies surveyed, with $44 \%$ requiring a prescription.

- Women continue to seek access in pharmacies in the setting of legal abortion; improving pharmacy staff knowledge and practices can help reduce unsafe abortion.

\section{INTRODUCTION}

Mexico City, one of Mexico's 32 states, legalised first-trimester abortion on request in 2007. Abortion is regulated at the state level, and first-trimester abortion is legal only under specific circumstances in other Mexican states. The majority of evidence about abortion in Mexico focuses on the public abortion programme, known as the Interrupcion Legal del Embarazo (ILE) programme, in Mexico City. ${ }^{1-4}$ Women also have access to services in the private sector, including private clinics, ${ }^{5}$ or by procuring misoprostol from a pharmacy with or without a prescription. While misoprostol was initially developed for treatment of ulcers, it is used in obstetrics and gynaecology to induce labour, treat haemorrhage, and induce pregnancy termination, which is sometimes also referred to as 'initiating return of menses'. ${ }^{67}$ Misoprostol was first made available in Mexican pharmacies in 1985 by prescription only. ${ }^{8}$ However, pharmacies do not have to register 
prescriptions (as they do for antibiotics, for example) and available data suggest that women across Latin America obtain misoprostol without a prescription. ${ }^{78}$

To date, research suggests a general lack of pharmacy staff knowledge about the use of misoprostol for abortion, including side effects, what the patient should expect, and effective dosing. ${ }^{78}$ This is an issue not only with misoprostol provision but also with other medical treatments provided directly in pharmacies in low- and middle-income countries worldwide. ${ }^{9}$ Yet women continue to seek access to medical abortion outside the clinic setting, even where abortion is legal, due to perceived ease of access, cost of services, and anonymity. ${ }^{2}$ Improving access and safe use of misoprostol through pharmacies can help reduce unsafe abortion. $^{10}$

There is limited evidence about the knowledge and sale habits of pharmacy staff in Mexico City following legalisation of first-trimester abortion. The purpose of this study was to describe availability of misoprostol, whether or not the pharmacy requires a prescription, knowledge of indications for misoprostol use, and legal status of abortion among pharmacy employees in Mexico City. We hypothesised that even after abortion became legal, women continue to seek misoprostol outside of clinics, as evidenced by sales habits of pharmacies. We also explored differences in knowledge and sales habits between small independent and chain pharmacies, and by gender of pharmacy staff.

\section{METHODS}

This study was a secondary analysis in collaboration with Ipas, a global non-profit focused on expanding access to safe abortion. Anonymous data were collected as part of an internal monitoring and evaluation project conducted by Ipas. No local institutional review board (IRB) approval was sought at the time of data collection. No Protected Health Information/ Health Insurance Portability and Accountability Act (PHI/HIPAA) identifiers were collected.

Pharmacies were randomly sampled from each of Mexico City's 16 delegaciones (similar to a zip code area) and stratified by large chain pharmacies (eg, Ahorro, Guadalajara) and small independent pharmacies ('mom-and-pop' establishments) within each delegacion. In June 2015 when the Ipas assessment was started, there were 1305 pharmacies in Mexico City, $35 \%$ of which were chains and $65 \%$ small independent establishments. The distribution of chain and independent pharmacies across Mexico City as well as the density of pharmacies in each delegacion guided the study sample composition. Some smaller delegaciones did not have enough small independent pharmacies to make up $65 \%$ of the sample, in which case those willing to participate were included. The final sample was 174 pharmacies. Data were collected JulyAugust 2015.
Research assistants approached one employee at each selected pharmacy and asked them to participate in the study. Following verbal informed consent the staff person answered questions about their sociodemographic and pharmacy training characteristics. They also answered questions about their practices related to sale of misoprostol, including need for prescription, sale frequency, and knowledge of indications for use. The survey did not specifically ask if they sold misoprostol for medical abortions. Dosing recommendations were not discussed since the focus was on availability not pharmacist recommendations. Data did not contain any identifiers; this secondary analysis was deemed non-human subjects research by the Oregon Health \& Science University IRB.

Our primary outcome was availability of misoprostol in the pharmacy. Secondary outcomes were requirement of a prescription for purchase, knowledge of indications for misoprostol use, knowledge of the legal status of abortion in Mexico City, and estimated frequency of requests for misoprostol. Other variables included demographic, employment, and educational information about the participating pharmacy staff.

We used descriptive and bivariate statistics. We tested for differences using Chi-square tests to compare our outcomes by pharmacy type (chain vs small independent) and gender of the respondent.

\section{RESULTS}

Of the 174 pharmacies, 65 (37\%) were chain and 109 (63\%) small independent, very similar to the known distribution of pharmacies in Mexico City. Respondents included 86 (49\%) male and 88 (51\%) female employees, with a roughly equal distribution between pharmacy types (table 1). The majority of interviewed employees at both types of pharmacies had completed at least some technical school (82\% in chain and 66\% in small independent pharmacies) and the sample included 21 licensed pharmacists, with no significant difference in education level of interviewees between pharmacy types $(p=0.735)$ (table 1$)$.

According to interviewed pharmacy employees, misoprostol was available at $61 \%$ of sites. Only $49 \%$ of independent pharmacies reported selling misoprostol,

\begin{tabular}{|c|c|c|c|c|}
\hline & $\begin{array}{l}\text { Overall } \\
(\mathrm{n}=174)\end{array}$ & $\begin{array}{l}\text { Chain } \\
\text { pharmacies } \\
(n=65)\end{array}$ & $\begin{array}{l}\text { Small } \\
\text { independent } \\
\text { pharmacies } \\
(\mathrm{n}=109)\end{array}$ & \\
\hline Characteristic & $\%(n)$ & $\%(95 \% \mathrm{Cl})$ & $\%(95 \% \mathrm{Cl})$ & $P$ value \\
\hline Male respondent & $\begin{array}{l}49.5 \\
(86)\end{array}$ & $\begin{array}{l}46 \\
\text { (34 to } 58 \text { ) }\end{array}$ & $\begin{array}{l}51 \\
\text { (42 to } 61 \text { ) }\end{array}$ & 0.505 \\
\hline $\begin{array}{l}\text { Formal pharmacy } \\
\text { training }\end{array}$ & $\begin{array}{l}28 \\
(48)\end{array}$ & $\begin{array}{l}29 \\
(18 \text { to } 40)\end{array}$ & $\begin{array}{l}27 \\
\text { (18 to } 35)\end{array}$ & 0.735 \\
\hline $\begin{array}{l}\text { Mean age (years) } \\
\text { (SD) }\end{array}$ & $\begin{array}{l}37.6(18-72) \\
(0.98)\end{array}$ & $\begin{array}{l}34 \\
(1.2)\end{array}$ & $\begin{array}{l}40 \\
(1.4)\end{array}$ & 0.635 \\
\hline
\end{tabular}


Table 2 Survey results

\begin{tabular}{|c|c|c|c|c|}
\hline Question & $\begin{array}{l}\text { Overall }(n=174) \\
\text { Percentage }(\%) \text { reporting } \\
\text { yes }(n)\end{array}$ & $\begin{array}{l}\text { Chain pharmacies }(\mathrm{n}=65) \\
\text { Percentage }(\%) \text { reporting } \\
\text { yes }(95 \% \mathrm{Cl})\end{array}$ & $\begin{array}{l}\text { Small independent } \\
\text { pharmacies }(n=109) \\
\text { Percentage }(\%) \text { reporting yes } \\
(95 \% \mathrm{Cl})\end{array}$ & $P$ value \\
\hline Is misoprostol sold? & $\begin{array}{l}61 \\
(106)\end{array}$ & $\begin{array}{l}82 \\
\text { (72 to 91) }\end{array}$ & $\begin{array}{l}49 \\
\text { (39 to 58) }\end{array}$ & $<0.001$ \\
\hline Is a prescription required? & $\begin{array}{l}44 \\
(76)\end{array}$ & $\begin{array}{l}42 \\
\text { (30 to } 54 \text { ) }\end{array}$ & $\begin{array}{l}45 \\
\text { (36 to } 54 \text { ) }\end{array}$ & 0.66 \\
\hline Is abortion legal? & $\begin{array}{l}80 \\
(139)\end{array}$ & $\begin{array}{l}80 \\
\text { (70 to 90) }\end{array}$ & $\begin{array}{l}80 \\
\text { (72 to 97) }\end{array}$ & 0.91 \\
\hline
\end{tabular}

compared with $81.5 \%$ of chain pharmacies $(\mathrm{p}<0.05)$ (table 2). Of the small independent pharmacies selling misoprostol, 72\% sold Cytotec, 21\% generic, and $7 \%$ had both types. Among chain pharmacies 36\% offered Cytotec, 38\% generic, and 26\% stocked both $(\mathrm{p}<0.001)$.

Fewer than half (44\%) of pharmacy staff reported requiring a prescription for sale of misoprostol. Among chain pharmacy employees, $41.5 \%$ reported requiring a prescription, while $50 \%$ of small independent pharmacy staff reported doing so (table 2). Nearly half $(48.8 \%)$ of male pharmacy staff reported requiring a prescription compared with $38.6 \%$ of females, but this difference was not statistically significant $(\mathrm{p}=0.18)$.

Eighty percent of respondents knew that abortion was legal in Mexico City, with no difference between pharmacy types $(80 \%$ of chain and $80 \%$ of small independent pharmacy employees) or gender of pharmacy worker (80.2\% of males, $79.6 \%$ of females)(table 2).

Knowledge of indications for misoprostol use was similar between independent and chain pharmacy staff. Most individuals were able to identify the outpatient indications (ulcers and abortion) but not the inpatient uses (haemorrhage, induction of labour). Though only $13.8 \%$ of chain and $8.2 \%$ of independent pharmacy employees correctly identified at least three out of five of the indications, the vast majority knew that it can be used to treat ulcers (74\% chain, $66 \%$ small independent; 69\% overall; $\mathrm{p}=0.66)$ and induce abortion (71\% chain, $61.5 \%$ small independent; $65 \%$ overall; $\mathrm{p}=0.33$ ) with no significant difference by pharmacy type (figure 1).

A larger proportion of respondents at pharmacies where misoprostol is sold reported knowing that misoprostol can be used for medical abortion $(71 \%$ vs $56 \% ; \mathrm{p}=0.045)$. Knowledge of abortion as an indication for misoprostol does not vary by requirement for a prescription $(\mathrm{p}=0.3)$

Most interviewees (75.4\%) reported $0-2$ requests for misoprostol per month, with no significant difference between pharmacy types. However, interviewees from six pharmacies reported 30 or more requests per month, all in different delegations, and one pharmacy reported 180 requests a month.

\section{DISCUSSION}

This study shows that misoprostol is widely available across pharmacies in Mexico City, but more available at large chain pharmacies than small independent ones, contrary to our hypothesis. Just under half report requesting a prescription, with female employees slightly less likely to require one. The difference by gender did not reach statistical significance, though it may be meaningful in practice, because it could impact women's access to misoprostol at the population level. Eighty percent of interviewed pharmacy workers know abortion is legal in Mexico City and the majority know that misoprostol can be used to induce abortion.

Our study found that misoprostol was available for sale at $61 \%$ of pharmacies surveyed, with $44 \%$ reporting that they required a prescription. This is comparable to other studies that have been done in Mexico and Latin America, ${ }^{7} 811$ though rates of prescription requirement were reportedly as low as $11 \%$ in the mystery client portion of one study. ${ }^{11}$ Misoprostol is expensive to keep in stock, which can be burdensome to small pharmacies who sell the medication infrequently, which may partially account for chain pharmacies being more likely to stock misoprostol than small independent pharmacies. Worldwide, there is significant variation in misoprostol availability, as well as how often misoprostol is recommended compared

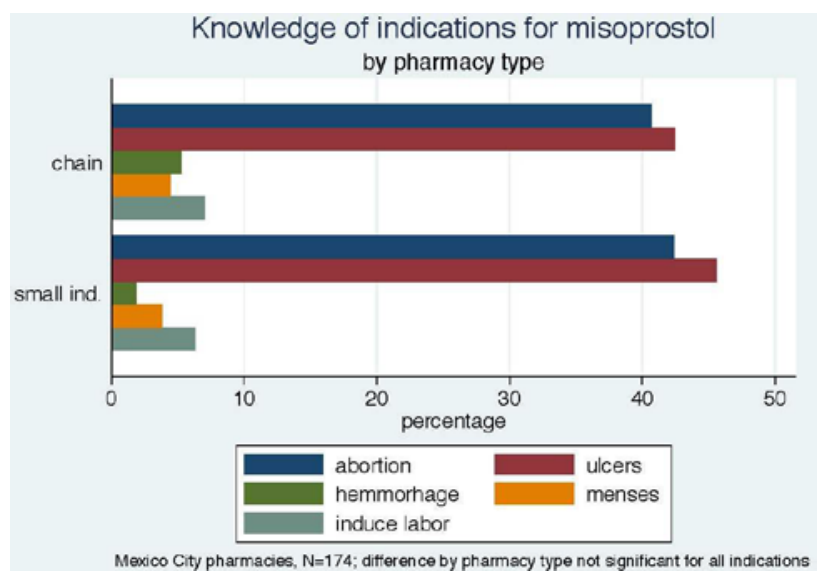

Figure 1 Knowledge of indications for misoprostol by pharmacy type. Ind, independent. 
with other medications when an abortifacient medication is requested at a pharmacy. ${ }^{10-15}$ The studies previously performed in Mexico and Latin America did not differentiate availability based on pharmacy type, though one did note that misoprostol was more likely to be sold by the pill rather than the bottle in independent pharmacies and low socioeconomic areas, which was used as a surrogate marker to indicate sale for use in medical abortion. ${ }^{8}$ It was also significantly more available in Mexico City, where abortion is presently legal, than in other areas of Mexico, where abortion is still legally restricted. ${ }^{8}$ Our study, undertaken after the decriminalisation of first-trimester abortion in Mexico City, suggests that women continue to access misoprostol outside of clinics, with some pharmacies requiring a prescription.

Mystery client studies previously performed in the region have focused on what medication is recommended when an abortifacient is requested and whether or not it is an effective method, as well as whether or not safety information and follow-up precautions are given. However, these studies were performed in areas where abortion is legally restricted, so are not directly comparable with our findings. Our data show that the majority of pharmacy staff know that misoprostol can be used for ulcers and to induce abortion, but are less familiar with other indications such as management of postpartum haemorrhage. This may be related to the fact that we surveyed only outpatient pharmacies. Prior studies around the world show wide variation in medication and dose recommendations given to women requesting medication to interrupt a pregnancy in settings with variable legal restrictions on abortion, ${ }^{10}$ demonstrating an ongoing need for additional education on safe and effective dosing, though this was not part of the present study.

We found that female pharmacy staff were slightly less likely than their male counterparts (39\% vs 49\%) to require a prescription, although this difference did not reach statistical significance. To our knowledge, only one previous study looked at differential prescription requirement by gender of the pharmacy worker, which also found that female staff were slightly more likely to require a prescription and sell by the pill, though the findings were not significant. ${ }^{8}$

Our results can be used to tailor interventions for pharmacy workers to improve the information women receive when requesting misoprostol, with or without a prescription. Educational interventions targeting pharmacy workers have been shown to be effective to improve referrals, information about medical abortion regimens and follow-up. ${ }^{16}{ }^{17}$ Training would obviously need to be region-specific, based on factors of legality, medication accessibility, and availability of follow-up. Even in a context of legal abortion and good access to services in the public and private sectors, women may choose to obtain misoprostol directly from pharmacies; this was not known in Mexico City.
Our results suggest that there is a need for educating pharmacy employees, since they are providing misoprostol directly to women, both with and without a prescription.

Our findings must be interpreted in light of several limitations. First, we relied on self-reported sales practices. Second, we did not ask about dosing recommendations. This study focused on availability, requirement of a prescription, and knowledge of indications. Our sample of pharmacies was designed to be representative of the distribution of chain and small independent pharmacies in Mexico City's delegaciones, yet there were localities where the target number of pharmacies could not be reached due to limited overall pharmacy numbers and willingness to participate. We may be underpowered for some comparisons; however, this descriptive study presents novel data on pharmacy practices in Mexico City after legalisation of abortion. The overall representation of pharmacies in all delegaciones of Mexico City, and inclusion of gender and educational diversity among staff, are strengths of the study. Additionally, social and religious biases, as well as utilising a survey method rather than the mystery client approach taken by other studies, could have contributed to underreporting of misoprostol availability and sales practices, even in the legal setting. However, our data do not allow us to assess whether underreporting occurred.

First-trimester medical abortion is legal and widely available in public and private sector clinics in Mexico City. Despite this, women still access misoprostol directly from pharmacies, with or without a prescription. Most pharmacy staff know that abortion is legal and that misoprostol can be used to induce abortion, but availability, knowledge of indications for use of misoprostol, and requirement of a prescription varies widely among pharmacies. This may result in variable access to misoprostol depending on the type pf pharmacy a woman walks into. Pharmacies may be a good place to target education for pharmacy employees and women about safe and effective use of misoprostol for abortion, whether through expanding knowledge of indications and appropriate dosing regimens, or improving access to information within pharmacies about abortion services available in Mexico City. Women will continue to seek access to medical abortion in pharmacies; therefore, improving pharmacy staff knowledge and practices can help reduce unsafe abortion.

Contributors RS and BGD conceived the analysis. MEC and RS led data collection. GW and BGD conducted the analysis. GW drafted the manuscript, BGD, RS, MEC and SK provided substantive revisions.

Funding Dr Blair Darney was supported by the Society of Family Planning (SFPRF11-02) and grant number K12HS022981 from the Agency for Healthcare Research and Quality. The content is solely the responsibility of the authors 
and does not necessarily represent the official views of the Agency for Healthcare Research and Quality.

Competing interests None declared.

Patient consent for publication Not required.

Provenance and peer review Not commissioned; externally peer reviewed.

Data availability statement Data are available upon reasonable request.

Open access This is an open access article distributed in accordance with the Creative Commons Attribution Non Commercial (CC BY-NC 4.0) license, which permits others to distribute, remix, adapt, build upon this work noncommercially, and license their derivative works on different terms, provided the original work is properly cited, appropriate credit is given, any changes made indicated, and the use is noncommercial. See: http://creativecommons.org/licenses/by-nc/4. $0 /$.

\section{ORCID iDs}

Greta Weaver http://orcid.org/0000-0002-9609-4421

Stephanie Küng http://orcid.org/0000-0003-2226-6355

Blair G Darney http://orcid.org/0000-0001-8120-028X

\section{REFERENCES}

1 Saavedra-Avendano B, Schiavon R, Sanhueza P, et al. Who presents past the gestational age limit for first trimester abortion in the public sector in Mexico City? PLoS One 2018;13:e0192547.

2 Friedman J, Saavedra-Avendaño B, Schiavon R, et al. Quantifying disparities in access to public-sector abortion based on legislative differences within the Mexico City metropolitan area. Contraception 2019;99:160-164.

3 Mondragón y Kalb M, Ahued Ortega A, Morales Velazquez $\mathrm{J}$, et al. Patient characteristics and service trends following abortion legalization in Mexico City, 2007-10. Stud Fam Plann 2011;42:159-66.

4 Becker D, Díaz Olavarrieta C. Decriminalization of abortion in Mexico City: the effects on women's reproductive rights. Am J Public Health 2013;103:590-3.

5 Schiavon R, Collado ME, Troncoso E, et al. Characteristics of private abortion services in Mexico City after legalization. Reprod Health Matters 2010;18:127-35.

6 Guttmacher Institute. Menstrual regulation and unsafe abortion in Bangladesh. Available: https://www.guttmacher. org/fact-sheet/menstrual-regulation-unsafe-abortion-bangladesh [Accessed 23 Mar 2019].

7 Billings DL, Walker D, Mainero del Paso G, et al. Pharmacy worker practices related to use of misoprostol for abortion in one Mexican state. Contraception 2009;79:445-51.

8 Lara D, García SG, Wilson KS, et al. How often and under which circumstances do Mexican pharmacy vendors recommend misoprostol to induce an abortion? Int Perspect Sex Reprod Health 2011;37:075-83.

9 Smith F. The quality of private pharmacy services in low and middle-income countries: a systematic review. Pharm World Sci 2009;31:351-61.

10 Footman K, Keenan K, Reiss K, et al. Medical abortion provision by pharmacies and drug sellers in low- and middleincome countries: a systematic review. Stud Fam Plann 2018;49:57-70.

11 Lara D, Abuabara K, Grossman D, et al. Pharmacy provision of medical abortifacients in a Latin American city. Contraception 2006;74:394-9.

12 Huda FA, Ngo TD, Ahmed A, et al. Availability and provision of misoprostol and other medicines for menstrual regulation among pharmacies in Bangladesh via mystery client survey. Int J Gynaecol Obstet 2014;124:164-8.

13 Reiss K, Footman K, Akora V, et al. Pharmacy workers' knowledge and provision of medication for termination of pregnancy in Kenya. J Fam Plann Reprod Health Care 2016;42:208-12.

14 Reiss K, Footman K, Burke E, et al. Knowledge and provision of misoprostol among pharmacy workers in Senegal: a cross sectional study. BMC Pregnancy Childbirth 2017;17:211.

15 Hendrickson C, Fetters T, Mupeta S, et al. Client-pharmacy worker interactions regarding medical abortion in Zambia in 2009 and 2011. Int J Gynaecol Obstet 2016;132:214-8.

16 Fetters T, Raisanen K, Mupeta S, et al. Using a harm reduction lens to examine post-intervention results of medical abortion training among Zambian pharmacists. Reprod Health Matters 2014;22:116-24.

17 Tamang A, Puri M, Lama K, et al. Pharmacy workers in Nepal can provide the correct information about using mifepristone and misoprostol to women seeking medication to induce abortion. Reprod Health Matters 2014;22:104-15. 